\title{
Effects of Large-Scale Research Funding Programs: A Japanese Case Study
}

\author{
Takanori Ida ${ }^{\text {a }}$ Naomi Fukuzawa ${ }^{a^{*}}$ \\ ${ }^{a}$ Graduate School of Economics, Kyoto University, Yoshida, Sakyo, Kyoto 606-8501, Japan
}

\begin{abstract}
This study investigates the effects of large-scale research funding from the Japanese government on the research outcomes of university researchers. To evaluate the effects, we use the difference-in-differences estimator and measure research outcomes in terms of number of papers and citation counts per paper. Our analysis shows that the funding program led to an increase in the number of papers in some fields and an increase in the citation counts in the other fields. A comparison of our estimation results with assessment data obtained from peer reviews showed important differences. Since the characteristics of research vary according to the field, bibliometrics analysis should be used along with the peer review method for a more accurate analysis of research impact.
\end{abstract}

Keywords: Research assessment; Difference-in-differences; Government grants; University research; Bibliometrics; Peer review

\footnotetext{
* Corresponding author. Tel.:+81-90-8374-1660

E-mail address: fukuzawa.naomi.62w@st.kyoto-u.ac.jp
} 


\section{Introduction}

In the report titled "Present Status of Research Evaluations and its Future in Japan," the Science Council of Japan has indicated that research evaluations play an important role in ensuring accountability in the use of research funds as well as in promoting research activities and improving their quality (Committee for Research Evaluations 2008). However, the same report has also highlighted that the research evaluation system of the Japanese government is not adequately developed and that research evaluation in Japan is a complex process, requiring considerable thought and effort from the evaluators and the evaluated academic units. In the United Kingdom, allocation of research grants to universities is based on the results of research evaluation process, known as the Research Assessment Exercise (RAE), which has already been undertaken six times. Although the RAE offers a prototype for evaluation methodology, it requires substantial inputs in terms of time and money (Kostoff, 1994; Oppenheim, 1995).

The purpose of this paper is to critically assess the performance of a large-sized research funding program in Japan, known as the $21^{\text {st }}$ Century Centers of Excellence (COE) Program, using a different evaluation technique: a bibliometric analysis. The aim of this funding program was to cultivate a competitive academic environment among Japanese universities by providing targeted support for the creation of world-class research and education bases. Nearly 6,000 researchers benefited from the COE program; however, their publication-related achievements have not been captured in a database. Institutions that applied for funds through the COE included $\mathrm{PhD}$ departments of graduate schools and university-affiliated research institutes. Applications for the COE program were reviewed by a team of 1,000 referees, each a specialist or leading authority in the subject field. Category-specific subcommittees evaluated the proposals through hearings and panel interviews. Applications were shortlisted by a screening committee, and the selection results were submitted to the program committee for final judgment. Applications for the COE program, which awarded research funding for a 5-year term, were accepted in FY 2002 (5 fields), FY 2003 (5 fields), and FY 2004 (1 field) ${ }^{1}$. Program performance was assessed by subject-specific subcommittees using peer review methods at a 2-year interval to

1 Details are given on the official site of the $21^{\text {st }}$ COE Program (http://www.jsps.go.jp/english/e-21coe/index.html) of the Japan Society for the Promotion of Science. 
verify the progress of the funded research projects, and final assessments were carried out after project completion.

In this study, we attempt to evaluate the effects of the COE program through bibliometric analysis, which overcomes the subjective biases of the peer review methods. To our knowledge, this is the first study that intends to evaluate the success of the COE program by analyzing its effects on the publication-related achievements of its recipients. Our analysis covers research achievements in eight fields recognized under the COE program: (1) life sciences; (2) information sciences, electrical and electronic engineering (henceforth, information sciences); (3) chemistry and material sciences; (4) humanities; (5) social sciences; (6) medical sciences; (7) mechanical, civil, architectural and other fields of engineering (henceforth, mechanical engineering); and (8) mathematics, physics, and earth sciences (henceforth, the mathematics and physics). Three interdisciplinary fields were excluded from the study as the research achievements in these fields were difficult to evaluate.

Data for bibliometric analysis of research outcomes is typically obtained from scientific databases. Previous studies have compared two scientific databases on the basis of the research outcomes reported by them: Web of Science (Thomson Reuters) and Scopus (Elsevier) (Meho and Yang, 2007; Norris and Oppenheim, 2007; Haddow and Genoni, 2010). Comparison results showed that Scopus could replace Web of Science as a tool to evaluate research impact. For this study, we used Scopus because of its comprehensive and accurate coverage of Japanese research outcomes. To construct the outcome indexes, we used the number of papers published by each researcher and the number of citations attributed to the researcher. We then employed the difference-in-differences (DID) estimator to evaluate the difference between "the before-after outcomes in the treatment group, which received funding" and "the before-after outcomes in the control group, which did not receive funding." Thus, we controlled for a certain number of selection biases that stemmed from nonrandom assignment of the COE program.

Although other studies have attempted to analyze the effects of funding programs with the help of control and treatment groups or with a before-after comparison, none of them have used DID estimation, which combines both treatment-control comparison and a before-after comparison to measure the effects of the treatment. Gaughan and Bozeman (2002) examined the effects of funding from the National Science Foundation (NSF) on the number of papers published. They found no significant difference in the total number of papers published between the treatment and 
control groups. Gaughan and Ponomariov (2008) compared their treatment group, consisting of researchers who received center support from the National Institute of Child Health and Human Development (NICHD), with a suitable control group and showed that the center affiliation did not have a significant influence on the publication rate. Gaughan (2009) compared the treatment and control groups of a training program at the National Institute of Health $(\mathrm{NIH})$ and showed that center affiliation did not have a significant impact on the paper publication rate adjusted by age. In a separate study, Bozeman and Gaughan (2007) showed that researchers who received industry grants or government grants had a higher involvement rate in the industry. The number of industry and government grants also had a significantly positive effect on industry involvement. Dietz and Bozeman (2005) compared the five-year mean publication rate of researchers who shifted from universities to industries and vice versa, and showed that the shift had an important effect on productivity.

The main results of this paper are summarized as follows. In the fields of life sciences, humanities, medical sciences, and mechanical engineering, we observed a statistically significant increase in the number of papers as a result of the COE program. A statistically significant increase in citation counts was also observed in the fields of life sciences fields, information sciences, and medical sciences.

However, caution must be exercised when interpreting the increased effects in different academic disciplines. In the natural sciences, the time lag between publication and citation is considered to be short; therefore, the effects of research funding are comparatively easy to ascertain. In the field of information sciences, there exists a stronger tendency to publish proceedings rather than journal articles. In social sciences and the humanities, the research cycle is longer, and the number of citations is lower. Thus, the field or discipline is a key factor affecting research evaluations.

This paper is organized as follows. Section 2 describes the indexes of research outcomes and the DID estimator method. Section 3 provides details on the scientific database used for the study and the method employed for selecting data. Section 4 explains the truncation biases of the citation counts and the DID estimator model. Section 5 describes the estimation results. Section 6 presents the discussions and conclusions.

\section{Methods}


In this section, we explain the indexes of research outcomes and the methods used for evaluating the effectiveness of a research support program.

\subsection{Indexes of research outcomes}

Peer review, as a method of research evaluation, is a costly and lengthy process and suffers from subjective biases, stemming from the "old boy" networks that exist in established fields and "halo" effects, which refer to the higher likelihood of funding for more prominent scientists (Gibbons and Georghiou, 1987; Kostoff, 1994; Oppenheim, 1995). To avoid these biases, this study uses number of papers and citation counts of individual researchers as measures of research outcomes. The use of number of papers and the citation counts, known as bibliometrics, to evaluate research credibility is known as an indirect peer review (Gibbons and Georghiou, 1987) and can be used as an alternative to peer reviews.

Many studies have investigated the correlation between peer review and bibliometrics (Anderson, et al., 1978; Zhu, et al., 1991; Oppenheim, 1995, 1997; Rinia, et al., 1998, 2001). For example, Oppenheim $(1995,1997)$ found a statistically significant correlation between the number of citations received by a department in total and the RAE rating of that department, derived from the peer-review method. Similarly, significant correlations between the two approaches were found in the fields of anatomy, archaeology, and genetics. Rinia et al. (1998) showed varying correlations between different bibliometric indicators and the results of peer evaluation of 56 research programs on condensed matter physics, carried out at universities or academic institutes in the Netherlands. In another study, Rinia et al. (2001) showed that the peer review results did not significantly correlate with the degree of interdisciplinarity and the number of publications per program; the total number of citations had a negative correlation with interdisciplinarity in physics in the Netherlands.

Although each discipline of study is unique, number of citations of patents is often used as an objective evaluation index for measuring patent value. Jaffe et al. (2000), Harhoff et al. (1999), and Lanjouw and Schankerman (1999) showed a positive correlation between the number of citations received by a patent and its importance (both economic and technological), as well as its quality and value. In line with the above studies, we use the number of papers as an activity index, 
while the citation counts reflect the quality of scientific research. Although the types of academic publication contained in the database included articles, conference papers, reviews, and letters, we restricted our analysis to only research articles, as these have passed through the most rigorous peer review.

\subsection{Treatment effect analysis}

The average treatment effect (ATE) is one of the methods of evaluating the effects of a research funding program (Rosenbaum and Rubin, 1983). ATE is the average difference between "the outcome with treatment, $y_{1}$ " and "the outcome without treatment, $y_{0}$ " It is defined as follows:

$$
\mathrm{ATE}=E\left(y_{1}-y_{0}\right)
$$

Let the variable $\mathrm{T}$ be a binary treatment indicator, where $\mathrm{T}=1$ denotes the treatment group and $\mathrm{T}=0$ denotes the control group. An important assumption in order to identify treatment effects is the conditional independence assumption or the strongly ignorable treatment assignment (Rosenbaum and Rubin, 1983), which states that conditional on a vector of observable variables $x$, the outcomes are independent of the treatment. The conditional independence assumption is written as follows:

$$
\begin{gathered}
\left(y_{1}, y_{0}\right) \mathrm{C} \mathrm{T} \mid x \\
0<p(\mathrm{~T}=1 \mid x)<1
\end{gathered}
$$

where C represents independence, following Dawid (1979), and the ATE is defined as follows:

$$
\begin{aligned}
\mathrm{ATE} & =E\left(y_{1}-y_{0} \mid x\right) \\
& =E\left(y_{1} \mid x\right)-E\left(y_{0} \mid x\right) \\
& =E\left(y_{1} \mid x, \mathrm{~T}=1\right)-E\left(y_{0} \mid x, \mathrm{~T}=0\right)
\end{aligned}
$$

Moreover, when the condition expressed in Eq. (2) holds, the average treatment effect on the treated (ATET) (Heckman and Robb, 1985) is defined by Eq. (4).

$$
\begin{aligned}
\mathrm{ATET} & =E\left(y_{1}-y_{0} \mid \mathrm{T}=1\right) \\
& =E\left(y_{1} \mid x, \mathrm{~T}=1\right)-E\left(y_{0} \mid x, \mathrm{~T}=1\right) \\
& =E\left(y_{1} \mid x, \mathrm{~T}=1\right)-E\left(y_{0} \mid x, \mathrm{~T}=0\right)=\mathrm{ATE}
\end{aligned}
$$

This is the expected value of the difference between "the results of the treatment" and "the results 
without the treatment" in the treatment group.

We thus estimate ATET when the treatment of the program involves random assignment. However, selection biases are inevitable in this case because the COE program is not based on random assignment. For this reason, we use the "difference-in-differences (DID)" estimator, explained in the following subsection.

\subsection{The difference-in-differences estimator}

The DID estimator is the difference between "the average change in $y$ in the treatment group over the course of the program" and "the average change in $y$ in the control group over the same time." We can disregard the unobservable individual-specific characteristics by comparing the same individual's research achievements before and after. By removing the time effects, we can measure only the effects of the treatment (Cameron and Trivedi, 2005; Lee, 2005; Stock and Watson, 2007; Wooldridge, 2002). Let "Before" and "After" represent the states before and after the program, respectively, and let "Treatment" and "Control" respectively refer to the treatment group and the control group. The DID estimator can be written as in Eq. (5) and represented as in Figure 1.

$$
\begin{aligned}
\mathrm{BA}^{\text {Treatment }} & =\{E(y \mid \mathrm{T}=1, \text { After })-E(y \mid \mathrm{T}=1, \text { Before })\} \\
\mathrm{BA}^{\text {Control }} & =\{E(y \mid \mathrm{T}=0, \text { After })-E(y \mid \mathrm{T}=0, \text { Before })\} \\
\mathrm{DID} & =\mathrm{BA}^{\text {Treatment }}-\mathrm{BA}^{\text {Control }}
\end{aligned}
$$

\section{$<$ Insert Figure 1 $>$}

Let $y_{\mathrm{b}}$ be the outcomes before the program, and let $y_{1 \mathrm{a}}$ be the outcomes after the program for the treatment group. Let $y_{0 \mathrm{a}}$ be the outcomes after the program for the non-treatment group. Then, the DID estimator can be written as follows:

$$
\mathrm{DID}=E\left(y_{1 \mathrm{a}}-y_{\mathrm{b}} \mid \mathrm{T}=1\right)-E\left(y_{0 \mathrm{a}}-y_{\mathrm{b}} \mid \mathrm{T}=0\right)
$$

Using Eq. (4), we can write

$$
\mathrm{ATET}=E\left(y_{\mathrm{la}}-y_{0 \mathrm{a}} \mid \mathrm{T}=1\right)
$$

When estimating ATET as the DID estimator, we assume the same time-effect condition: "the 
effects of not belonging to the treatment group are the same between the treatment group and the control group."

$$
E\left(y_{0 \mathrm{a}}-y_{\mathrm{b}} \mid \mathrm{T}=1\right)=E\left(y_{0 \mathrm{a}}-y_{\mathrm{b}} \mid \mathrm{T}=0\right)
$$

Then we have

$$
\mathrm{DID}=E\left(y_{1 \mathrm{a}}-y_{\mathrm{b}} \mid \mathrm{T}=1\right)-E\left(y_{0 \mathrm{a}}-y_{\mathrm{b}} \mid \mathrm{T}=0\right)=E\left(y_{1 \mathrm{a}}-y_{0 \mathrm{a}} \mid \mathrm{T}=1\right)=\text { ATET } .
$$

We measured the program effects assuming Eq. (7) holds ${ }^{2}$. In this study, the control group was formulated by extracting researchers randomly from the same university, the same graduate school, and the same major as the ones in the treatment group. Further, the indirect effects of belonging to the selected university were offset by using the DID estimator, which can estimate only the direct effects.

\section{Data}

In this section, we describe the scientific database used in this study and explain the process of obtaining data.

\subsection{Database selection}

Previous studies on research evaluation using bibliometrics have relied on either Web of Science (WoS) or Scopus, both of which are international scientific databases. Meho and Yang (2007) compared the ranking of the citation counts (published between 1996 and 2005) between WoS and Scopus for 15 faculty members of the School of Library and Information Science at Indiana University, Bloomington, and found that the overall relative ranking of the faculty members did not change significantly between the two data sources. Norris and Oppenheim (2007) compared four scientific databases (WoS, Scopus, Google Scholar, and CSA Illumina) by using data from the RAE (2001) and from the International Bibliography in the Social Sciences, which includes non-English journals in the field. They concluded that Scopus offered the best coverage and could replace WoS as a tool to evaluate research impact in the social sciences fields.

A key concern in this analysis was identifying researchers correctly using the search function

2 This condition is weaker than the random assignment condition in Eq. (2). 
in the databases. We compared WoS and Scopus from this perspective and found that although WoS facilitated a longer-term analysis, it did not allow users to perform a full name search, which made it difficult to identify the researchers. Scopus, on the other hand, assigned author IDs to prominent researchers, facilitating full name search. Hence, we decided to use Scopus as the database for this study ${ }^{3}$.

\subsection{Data on research outcomes}

The author ID function on the Scopus database was not completely error-free, leading to problems especially in identifying authors whose affiliations had changed. To solve this problem, we first compiled a list that included details of the researchers' affiliations and departments at the start of the COE program, from the official COE website. We then searched for published papers and citations counts of each researcher. To avoid problems in data accuracy, the collected data were filtered by matching their affiliations and departments listed in the published papers to those at the start of the COE program. Since this process could lead to the accidental omission of researchers who had changed their affiliations a number of times, we contacted each researcher via e-mail address and confirmed the list of publications with each researcher (researcher's self-check). Added to this, we excluded researchers who had enrolled but left the COE program within a 5 -year term.

To form the control group (researchers not engaged in the COE program), we randomly chose researchers from each university selected in the program. The ratios of full professors, divisions, and majors between the treatment and control groups were equalized. The number of teams and researchers used for analysis and the results of the researcher's self-check are summarized in Table 1.

$<$ Insert Table 1 $>$

To avoid any selection biases resulting from the researcher's self-check, we analyzed the difference between the "before-after outcomes of researchers who replied to self-check e-mail"

${ }^{3}$ A drawback of the Scopus database is that it includes citation counts only since 1996 . However, since we have used data only after 1997, this drawback did not affect our analysis. 
and "before-after of the outcomes of researchers who did not reply to the self-check e-mail" using a $t$-test of the number of papers. Because the null hypothesis of no difference could not be rejected in all fields at a 5\% level of statistical significance, we conclude that the biases are not serious.

\section{Estimation models}

\subsection{Truncation bias of the citation counts}

One of the major problems associated with the use of citation counts is truncation bias. The decline in the citations of recent papers is a result of such truncation. To address this problem, some studies have used normalization, which is also used with forward citation of patents (Jaffe and Trajtenberg, 1996; Jaffe and Lerner, 2001; Hall et al., 2000, 2001). There are two approaches of normalization: the fixed-effects approach and the quasi-structural approach (Hall et al., 2001). The fixed-effects approach assumes normalization by dividing each citation by the corresponding year-field citation mean. The quasi-structural approach attempts to distinguish the multiple effects on citation via econometric estimation.

In this paper, we estimated the fixed effects using an eclectic mix of the two above-mentioned methods. Let the dependent variable be the citation counts per paper. We reviewed citation data from 1997 to 2007 for the fields funded by the COE program in FY 2002, and data from 1998 to 2008 for the fields funded by the COE program in FY 2003. We use the year dummy variable as an independent variable ${ }^{4}$. The regression equation is shown below:

$$
\text { Cited }^{p}{ }_{i t}=\alpha+\beta d_{i t}^{\text {year }}+u_{i t}
$$

Cited $^{p}{ }_{i t} \quad:$ citation counts per paper for year $t$ of researcher $i$

$d_{i t}^{\text {year }} \quad$ : year dummy variable with some base year

We used the least-squares method for each team of the treatment group and the control group. We subtracted the "estimated amount in each year" from the "citation counts in each year" because this estimated amount is negative, given that there is underestimation by truncation.

${ }^{4}$ We used 1998 as the base year for the fields incorporated in the COE program of FY 2002, and 1999 for the fields incorporated in the COE program of FY 2003. 


\subsection{Difference-in-differences estimator models}

We conducted a linear panel regression analysis using ten years of data for each researcher, excluding the year of program adoption. The regression model is shown below.

$$
\begin{aligned}
\text { Paper }_{i t} & =\gamma_{0}+\gamma_{1} d_{i}^{\text {treat }}+\gamma_{2} d_{i t}^{\text {After }}+\delta d_{i}^{\text {treat }} d_{i t}^{\text {After }}+\varepsilon_{i t} \\
\text { Cited }_{i t}^{\text {adjusted }} & =\gamma_{0}^{\prime}+\gamma_{1}^{\prime} d_{i}^{\text {treat }}+\gamma_{2}^{\prime} d_{i t}^{\text {After }}+\delta^{\prime} d_{i}^{\text {treat }} d_{i t}^{\text {After }}+\varepsilon_{i t}
\end{aligned}
$$

Paper $_{i t} \quad:$ total number of papers in year $t$ of researcher $i$

Cited $_{i t}^{\text {adjusted }} \quad:$ adjusted number of citations per paper per year of researcher $i$

$d_{i}^{\text {treat }} \quad:$ dummy variable indicating the researcher selected by the program

$d_{i t}^{\text {After }} \quad:$ dummy variable of the time period after the program

The DID estimator of the number of papers and citation counts is $\delta$ in Eq. (9) and $\delta^{\prime}$ in Eq. (10), respectively.

\section{Estimation results}

In this section, we describe the DID estimation results. The DID estimation results for the eight science fields analyzed in this study are shown in Table 2. Results of the average increased effects in the number of papers and citations are shown in Tables 3-10. After performing a Hausman's specification test, we were not able to reject the null hypothesis that "there is no correlation between the individual characteristics effect and the independent variables" in all the fields. Consequently, we adopted a random-effects model. We explain the results in detail below.

$$
<\text { Insert Table } 2>
$$

\subsection{Life sciences}

In the fields of life sciences, we found a statistically significant increase in the number of papers and citations. The main results are given as below. 
- The number of papers per researcher per year increased from 3.08 to 4.38 after the introduction of the COE program. The COE effect accounted for 0.71 of total increase $(\Delta 1.30)$, which was statistically significant at the $1 \%$ level. Moreover, the citation counts per paper increased from 28.56 to 37.39 after the COE program $(\Delta 8.83)$. The COE effect amounted to 4.67 , which was also statistically significant at the $1 \%$ level.

- We obtained statistically significant results for the number of papers authored by 13 teams out of a total of 28 teams. We also obtained statistically significant results for the citation counts of 5 teams.

- The effects of the COE program on national and public universities (22 teams) were compared with those on private universities (6 teams). The number of papers per researcher per year increased by 0.7 and 0.1 , respectively. Similarly, citation counts per paper increased by 6.4 and 1.5, respectively (see Table 3 ).

- With regard to specific disciplines, biological sciences witnessed the highest increase in the number of papers, while the disciplines of life science and biological mechanisms and functions witnessed the highest increase in citation counts.

- We compared the results of the peer review methods with our estimation results. The three teams that had obtained the highest peer review assessment were among the 13 teams shown to have significant impact on the number of papers, in our estimation. Further, the two teams that had received the highest peer review assessment were among the 5 teams shown to have significant effects on the citation counts, in our estimation.

$<$ Insert Table $3>$

\subsection{Information sciences and electrical and electronic engineering}

In the field of information sciences, we found a statistically significant increase in the number of citations. The main results are given below.

- The number of papers per researcher per year increased from 1.75 to 2.32 after the introduction of the COE program $(\Delta 0.57)$. The COE effect accounted for 0.02 , which was not statistically significant. The citation counts per paper increased from 5.89 to 8.12 after 
the implementation of the program. Of the total increase $(\Delta 2.23)$, the COE effect was 1.49 , which was statistically significant at the $5 \%$ level.

- We obtained statistically significant results for the number of papers by 4 teams out of a total of 20. Statistically significant results were also obtained for the citation counts of 5 teams.

- Within national universities (15 teams), the number of papers per researcher per year increased by 0.1 ; however, no such increase was found for the teams in the private universities ( 5 teams). Further, citation counts per paper increased by 0.9 and 4.8 , respectively (see Table 4).

- Classification of effects according to graduate course showed that graduate schools of science and engineering witnessed the highest increase in citation counts.

- Comparison of our estimation results with the peer review analysis showed the following: one team, among 4, that received the highest peer review assessment had a significant effect on the number of papers, in our model. Similarly, the team that received the highest peer review assessment from among 5 teams had a significant impact on the citation counts, in our analysis.

$<$ Insert Table $4>$

\subsection{Chemistry and material sciences}

In the fields of chemistry and material sciences, no statistically significant increase in numbers of papers or citation counts was observed. The main results are summarized below.

- The number of papers per researcher per year increased from 4.57 to $5.87(\Delta 1.30)$. The COE effect was 0.32 , which was not statistically significant. Citation counts per paper increased from 13.75 to 16.19 after the implementation of the program. COE was responsible for 0.12 of the total increase $(\Delta 2.44)$, which was not statistically significant.

- Statistically significant results were obtained for the number of papers authored by 2 teams out of a total of 21 teams. Results were also statistically significant for the citation counts of one team. 
- Within national universities (18 teams) and private universities (3 teams), the number of papers per researcher per year increased by 0.3 and 0.4 , respectively. The citation counts per paper decreased by 0.1 and increased by 1.0, respectively (see Table 5).

- Graduate schools of science experienced the highest increase both in the number of papers and citation count.

- The team that received the highest peer review assessment among 2 teams had significant effects, in our model, on the number of papers. Further, one team that did not receive the highest peer review assessment had significant effects, in our model, on the citation counts.

\section{$<$ Insert Table $5>$}

\subsection{Humanities}

Within humanities, we found a statistically significant increase in the number of papers. The main results are as follows.

- The number of papers per researcher per year increased from 0.12 to 0.19 after the introduction of COE program $(\Delta 0.07)$. The COE effect was 0.04 , statistically significant only at the $10 \%$ level. Citation counts per paper increased from 0.79 to $0.96(\Delta 0.17)$. Although COE effect was exclusively responsible for this increase in citations, the value was not statistically significant.

- We obtained statistically significant results for the number of papers, which were written by 2 out of 20 teams. However, no significant results were obtained for citation counts.

- Within national and public universities (14 teams), the number of papers per researcher per year increased by 0.1 ; however, no such increase was found for the teams in the private universities (6 teams). Similarly, citation counts per paper increased by 0.2 and 0.1 , respectively (see Table 6).

- Among graduate courses, the field of psychology witnessed the highest increase both of in the number of papers and citation count.

- The team that received the highest peer review assessment among 2 teams had significant effect in terms of the number of papers, in our model. 
$<$ Insert Table 6>

\subsection{Social sciences}

In the field of social sciences, no statistically significant increase was observed for the number of papers or citation counts. The main results are given below.

- The number of papers per researcher per year increased from 0.15 to 0.23 after the COE program. Of the total increase $(\Delta 0.08)$, the COE effect accounted for 0.03 , which was not statistically significant. The citation counts per paper increased from 0.70 to 0.99 after the implementation of the program $(\Delta 0.29)$. The COE effect was 0.12 , which was not a statistically significant value.

- We obtained statistically significant results for the number of papers from 3 out of 25 teams. No such significant results were obtained for citation counts.

- In national universities (17 teams) and private universities (8 teams), the number of papers per researcher per year increased by 0.05 and decreased by 0.03 , respectively. Citation counts per paper increased by 0.29 and decreased by 0.03 , respectively (see Table 7).

- In terms of subject areas within the social sciences, economics and policy studies witnessed the highest increase in the number of papers and citations. The relatively higher academic performance in economics can be attributed to the fact that researchers in this field tend to publish in international English journals more often than researchers working in the other social sciences fields. The increase in the number of published economics papers was 0.12 , statistically significant at the $1 \%$ level. Although the increase in the number of citation counts was 0.34 , the value was not statistically significant.

- The 3 teams having significantly positive impact on the number of papers in our analysis had received the highest peer review assessments. However, 8 other teams that did not have a significantly positive impact on the number of papers in our estimation fared well on the peer review assessment because the training offered to the graduate students in their universities and the novelty of their research studies were highly evaluated.

$<$ Insert Table 7 $>$ 


\subsection{Medical sciences}

A statistically significant increase in the number of papers and citations was reported in the field of medical sciences. The main results are as under.

- The number of papers per researcher per year increased from 4.22 to 6.71 once the COE program was introduced $(\Delta 2.49)$. The COE effect was 1.06 , which was statistically significant at the $1 \%$ level. Citation counts per paper increased from 25.22 to 31.17 . The COE effect was 3.43 of the total increase $(\Delta 5.94)$, which was statistically significant at the $5 \%$ level.

- We obtained statistically significant results for the number of papers from 15 teams out of a total of 35 teams. Statistically significant results were also obtained for the citation counts by 8 teams.

- In national and public universities (26 teams) and private universities ( 9 teams), the number of papers per researcher per year increased by 1.1 and 0.7 , and citation counts per paper increased by 4.1 and 2.6, respectively (see Table 8).

- Graduate schools of medicine accounted for the highest increase in the number of papers and citations.

- Eleven of 15 teams that had a significantly positive effect on the number of papers in our model had received the highest peer review assessment. Similarly, 5 of 8 teams with significantly positive effects on the citation counts, in our model, had received the highest the peer review assessment.

$<$ Insert Table $8>$

\subsection{Mechanical, civil, architectural and other fields of engineering}

In mechanical engineering and allied fields, we found a statistically significant increase in the number of papers. The following are the main results. 
- The number of papers per researcher per year increased from 0.87 to 1.47 after the introduction of the COE program. Of the total increase $(\Delta 0.60)$, the COE effect was 0.34 , statistically significant at the $1 \%$ level. Moreover, the citation counts per paper increased from 3.63 to 5.43 after the program was launched $(\Delta 1.80)$. The COE effect was 0.42 , which was not statistically significant.

- In terms of the number of papers, we obtained statistically significant results from 7 out of a total of 22 teams. For citation counts, we obtained statistically significant results from 2 teams.

- Comparison of the COE effects between national and public universities (17 teams) and private universities ( 5 teams) showed that the number of papers per researcher per year increased by 0.4 and decreased by 0.1 , respectively. Further, citation counts per paper increased by 0.9 and decreased by 1.0 , respectively (see Table 9).

- Out of a total of 7 teams that had a significant impact on the number of the papers in our model, three teams had received a high peer review assessment. Similarly, the team that received the highest peer review assessment was among the 2 teams that had a significantly positive impact on the citation counts, in our model.

$<$ Insert Table 9 $>$

\subsection{Mathematics, physics, and earth sciences}

In the fields of mathematics, physics, and earth sciences, no statistically significant increase was observed in the number of papers or citations. The main results are summarized below.

- The number of papers per researcher per year increased from 1.88 to 2.31 after the implementation of the COE program $(\Delta 0.43)$. We found a negative COE effect of -0.15 , which was not statistically significant. The citation counts per paper increased from 9.20 to 10.59 once the program began. The COE effect accounted for -2.46 of the total increase $(\Delta 1.39)$. Because the before-after outcomes in the control group ( $\mathrm{BA}^{\mathrm{Control}}$ ) exceeded those of the treatment group ( $\mathrm{BA}^{\text {Treatment }}$ ), these fields have negative effects (see Eq.(5)).

- We obtained statistically significant results for the number of papers authored by 1 out of a 
total of 23 teams. No such significant results were obtained for the citation counts in any team.

- In national and public universities (21 teams) and private universities ( 2 teams), the number of papers per researcher per year decreased by 0.1 and 0.3 , respectively. Further, the citation counts per paper decreased by 2.4 and 2.0, respectively (see Table 10).

- Comparison between our estimation results and those of the peer review showed that one team that had not received the highest peer review assessment had significant effects on the number of papers in our model. The negative evaluation in the peer review assessment was attributed to a decrease in the enrollment of doctoral course students and lack of novelty in research achievements, which only seemed to extend conventional research.

$<$ Insert Table 10 $>$

\section{Discussion and Conclusion}

The results above confirm that the positive impact of the $21^{\text {st }} \mathrm{COE}$ program, measured in terms of increase in the number of papers and citation counts, differs across research fields. The fields of life sciences and medical sciences have experienced the maximum impact of the COE program, both in terms of number of papers and citations. Having said that, one must also note that research cycles are remarkably different across fields, and the level and scale of the achievements in each research field before the introduction of the program was not the same (see Table 2). For instance, there are a great number of Japanese books and journals in the fields of social sciences and humanities ${ }^{5}$.

Haddow and Genoni (2010) compared the four-tier ranking of the Australian social science journals by Excellence in Research for Australia (ERA) with the citation-based indicators for these journals derived from WoS and Scopus databases. They showed that the correlation between the journal rank and citation counts was low. Further, the database coverage of journals in the social sciences was poor, whereas natural sciences journals were more easily cited, with shorter time lag between publication and citation.

${ }^{5}$ In future, we may perform a DID estimation using the number of Japanese books in these fields along with English-only journal papers and citations, from another database. 
One of the limitations of this study is that we may not have succeeded in accurately capturing the research trends specific to each field of study as we did not include the publications in proceedings. Only journal articles were used in this analysis, because they are considered as final achievements. We calculated the ratio of publications in proceedings for the teams that had a significantly positive impact on the papers and citations. In the field of life sciences, this ratio was $5 \%$, whereas it was $44 \%$ in the information sciences.

The differences, as mentioned above, in the research and education styles across fields make it difficult to determine the field that received the highest policy impact. One of the best approaches to adjust for the differences among fields and to compensate for this demerit of quantitative bibliometrics is the peer review. Bibliometric indexes play a supporting role and supplement the peer review with important information (Rinia et al., 1998). Thus, evaluation by a field-specific expert, as in a peer review, and econometric analysis, based on an individual researcher's achievements, have different merits and demerits.

In our study, we identified a few discrepancies between the results of the econometric analysis and the peer review. For instance, despite their significantly positive impact on the number of papers or citations, some teams did not fare well in the peer review. This was because peer reviews typically offered unfavorable evaluations for aspects related to the training of researchers and their collaborative research within a team. In other cases, the peer reviewers felt that research papers lacked novelty or original thought.

On the other hand, some teams that did not have a statistically significant impact on the number of papers or citation counts in our model received a favorable peer review assessment. This could be attributed to the highly positive evaluation of the training and research uniqueness.

Our study also has the following limitations. First, the educational component of the COE program was as important as the research component, and it aimed to develop excellent researchers. Although a peer review considers these aspects, we did not use any index to evaluate these educational aspects of the program. Second, it is difficult to evaluate the creativity and novelty of research activities through number of papers and citations in a short-term (five years) evaluation. For a more effective evaluation, both peer reviews and econometric evaluation methods should be used together. 


\section{References}

Anderson, R., Narin, F. and McAllister, P., 1978. Publication Ratings versus Peer Ratings of Universities. Journal of The American Society for Information Science 29, 91-103.

Bozeman, B. and Gaughan, M., 2007. Impacts of Grants and Contracts on Academic Researchers' Interactions with Industry. Research Policy 36, 694-707.

Cameron, A. and Trivedi, P. (2005). Microeconometrics: Methods and Applications. Cambrige University Press, pp.860-898.

Committee for Research Evaluations, 2008. Present Status of Research Evaluations and its Future in Japan. Science Council of Japan.

Dawid, A., 1979. Conditional Independence in Statistical Theory. Journal of the Royal Statistical Society, Series B(Methodological) 41, 1-31.

Dietz, J. and Bozeman, B., 2005. Academic Careers, Patents, and Productivity: Industry Experience as Scientific and Technical Human Capital. Research Policy 34, 349-367.

Gaughan, M. and Bozeman,B., 2002. Using Curriculum Vitae to Compare Some Imapcts of NSF Research Grants with Research Center Funding. Research Evaluation 11, 17-26.

Gaughan, M. and Ponomariov, B., 2008. Faculty Publication Productivity, Collaboration, and

Grants Velocity: Using Curricula Vitae to Compare Center-Affiliated and Unaffiliated Scientists. Research Evaluation 17, 103-110.

Gaughan, M., 2009. Using the Curriculum Vitae for Policy Research: An Evaluation of National

Institutes of Health Center and Training Support on Career Trajectories. Research Evaluation 18, 117-124.

Gibbons, M. and Georghiou, L., 1987. Evaluation of Research: A Selection of Current Practices. Organisation for Economic Co-operation and Development, Paris.

Haddow, G and Genoni,P., 2010. Citation Analysis and Peer Ranking of Australian Social Science Journals. Scientometrics 85, 471-487.

Hall, B., Jaffe, A. and Trajtenberg, M., 2000. Market Value and Patent Citations: A First Look. NBER Working Paper 7741.

Hall, B., Jaffe, A. and Trajtenberg, M., 2001. The NBER Patent Citations Data File: Lessons, Insights and Methodological Tools. NBER Working Paper 8498.

Harhoff, D., Narin, F., Scherer, F. and Vopel, K., 1999. Citation Frequency and the Value of 
Patented Inventions. The Review of Economics and Statistics 81, 511-515.

Heckman, J. and Robb, R., (1985). Alternative Methods for Evaluating the Impact of Interventions, in Heckman,J. and Singer, B. eds. Longitudinal Analysis of Labor Market Data, New York: Cambridge University Press, pp.156-245.

Jaffe, A. and Lerner, J., 2001. Reinviting Public R\&D: Patent Policy and the Commercialization of National Laboratory Technologies. RAND Journal of Economics 32, 167-198.

Jaffe, A. and Trajtenberg, M., 1996. Flows of Knowledge from Universities and Federal Laboratories: Modeling the flow of Patent Citations over Time and Across Institutional and Geographic Boundaries. Proceedings of the National Academy of Sciences 93, 12671-12677.

Jaffe, A., Trajtenberg, M. and Fogarty, M., 2000. The Meaning of Patent Citations: Report of the NBER/Case-Western Reserve Survey of Patentees. NBER Working Paper 7631.

Kostoff, R., 1994. Federal Research Impact Assessment: State-of-the-Art. Journal of the American Society for Information Science 45, 428-440.

Lanjouw, J. and Schankerman, M., 1999. The Quality of Ideas: Measuring Innovation with Multiple Indicators. NBER Working Paper 7345.

Lee, M.-J., 2005. Micro-Econometrics for Policy, Program, and Treatment Effects. New York, Oxford University Press.

Meho, L. and Yang, K., 2007. Impact of Data Sources on Citation Counts and Rankings of LIS Faculty: Web of Science versus Scopus and Google Scholar. Journal of the American Society for Information Science and Technology 58, 2105-2125.

Norris, M. and Oppenheim, C., 2007. Comparing Alternatives to the Web of Science for Coverage of the Social Sciences' Literature. Journal of Informetrics 1, 161-169.

Oppenheim, C., 1995. The Correlation Between Citation Counts and the 1992 Research Assessment Exercise Ratings for British Library and Information Science University Departments. Journal of Documentation 51, 18-27.

Oppenheim, C., 1997. The Correlation Between Citation Counts and the 1992 Research Assessment Exercise Ratings for British Research in Genetics. Anatomy and Archaeology. Journal of Documentation 53, 477-487.

Rinia, E., van Leeuwen, Th., van Vuren, H. and van Raan, A., 1998. Comparative Analysis of a Set of Bibliometric Indicators and Central Peer Review Criteria Evaluation of Condensed 
Matter Physics in the Netherlands. Research Policy 27, 95-107.

Rinia, E., van Leeuwen, Th., van Vuren, H., and van Raan, A., 2001. Influence of Interdisciplinarity on Peer-Review and Bibliometric Evaluations in Physics Research. Research Policy 30, 357-361.

Rosenbaum, P. and Rubin, D., 1983. The Central Role of the Propensity Score in Observational Studies for Causal Effects. Biometrika 70, 41-55.

Stock, J. and Watson, M., (2007). Introduction to Econometrics: International ed. Pearson/Addison-Wesley, 2nd ed., pp.468-519.

Wooldridge, J., (2002). Econometric Analysis of Cross Section and Panel Data. The MIT Press, pp.603-643.

Zhu, J., Meadows, A. and Mason, G., 1991. Citations and Departmantal Research Ratings. Scientometrics 21, 171-179. 
Figure 1: The Difference-in-differences estimator

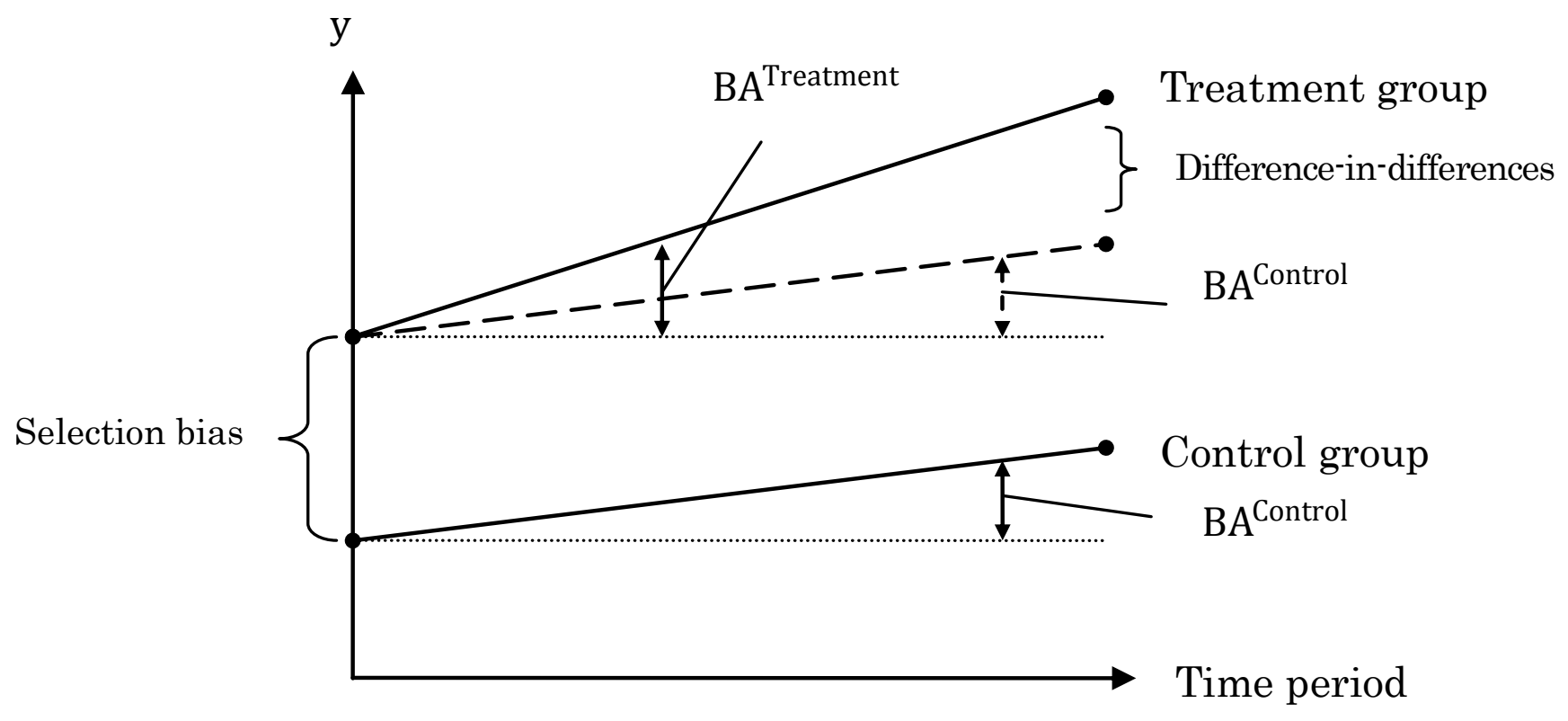

Source: We created this figure based on Stock and Watson(2007), p.482. 
Table 1: The number of researchers, teams, and the result of the researcher's self-check

\begin{tabular}{|c|c|c|c|c|c|c|c|c|}
\hline & \multicolumn{4}{|c|}{ Adopted in FY 2002} & \multicolumn{4}{|c|}{ Adopted in FY 2003} \\
\hline & $\begin{array}{l}\text { Life } \\
\text { sciences }\end{array}$ & $\begin{array}{l}\text { Information } \\
\text { sciences }\end{array}$ & $\begin{array}{c}\text { Che mistry, material } \\
\text { sciences }\end{array}$ & Humanities & $\begin{array}{c}\text { Social } \\
\text { sciences }\end{array}$ & $\begin{array}{c}\text { Medical } \\
\text { sciences }\end{array}$ & $\begin{array}{l}\text { Mechanical } \\
\text { engineering }\end{array}$ & $\begin{array}{c}\text { Mathe matics and } \\
\text { physics }\end{array}$ \\
\hline The number of teams & 28 & 20 & 21 & 20 & 25 & 35 & 22 & 23 \\
\hline $\begin{array}{l}\text { The number of researchers } \\
\text { in the treatment group }\end{array}$ & 419 & 360 & 389 & 316 & 441 & 510 & 333 & 397 \\
\hline $\begin{array}{l}\text { The number of researchers } \\
\text { in the control group }\end{array}$ & 109 & 102 & 102 & 93 & 125 & 137 & 98 & 109 \\
\hline Sent an e-mail (proportion) & $282(67 \%)$ & $263(73 \%)$ & $254(66 \%)$ & $14(15 \%)$ & $107(49 \%)$ & $264(53 \%)$ & $163(58 \%)$ & $227(70 \%)$ \\
\hline Obtained a reply (proportion) & $163(58 \%)$ & $127(48 \%)$ & $110(43 \%)$ & $9(64 \%)$ & $62(58 \%)$ & $145(55 \%)$ & $68(42 \%)$ & $113(50 \%)$ \\
\hline
\end{tabular}


Table 2: The DID estimation results for the eight sciences fields

The increased effects of the number of papers per researcher per year

\begin{tabular}{|c|c|c|c|c|c|c|c|c|}
\hline & \multicolumn{4}{|c|}{ Adopted in FY 2002} & \multicolumn{4}{|c|}{ Adopted in FY 2003} \\
\hline & $\begin{array}{c}\text { Life } \\
\text { sciences }\end{array}$ & $\begin{array}{l}\text { Information } \\
\text { sciences }\end{array}$ & $\begin{array}{c}\text { Che mistry, material } \\
\text { sciences }\end{array}$ & Humanities & $\begin{array}{c}\text { Social } \\
\text { sciences }\end{array}$ & $\begin{array}{c}\text { Medical } \\
\text { sciences }\end{array}$ & $\begin{array}{l}\text { Mechanical } \\
\text { engineering }\end{array}$ & $\begin{array}{c}\text { Mathe matics and } \\
\text { physics }\end{array}$ \\
\hline Before the $\mathrm{COE}$ & 3.08 & 1.75 & 4.57 & 0.12 & 0.15 & 4.22 & 0.87 & 1.88 \\
\hline After the $\mathrm{COE}$ & 4.38 & 2.32 & 5.87 & 0.19 & 0.23 & 6.71 & 1.47 & 2.31 \\
\hline Natural increases & 0.59 & 0.55 & 0.97 & 0.03 & 0.05 & 1.42 & 0.26 & 0.58 \\
\hline The COE effects & $\begin{array}{r}0.709 * * * \\
(0.126) \\
\end{array}$ & $\begin{array}{l}0.0221 \\
(0.118) \\
\end{array}$ & $\begin{array}{r}0.325 \\
(0.297) \\
\end{array}$ & $\begin{array}{r}0.0386 * \\
(0.0201) \\
\end{array}$ & $\begin{array}{r}0.0325 \\
(0.0210) \\
\end{array}$ & $\begin{array}{r}1.065 * * * \\
(0.179) \\
\end{array}$ & $\begin{array}{r}0.336 * * * \\
(0.0827) \\
\end{array}$ & $\begin{array}{r}-0.150 \\
(0.0987) \\
\end{array}$ \\
\hline
\end{tabular}

The increased effects of the citation per paper

\begin{tabular}{|c|c|c|c|c|c|c|c|c|}
\hline & \multicolumn{4}{|c|}{ Adopted in FY 2002} & \multicolumn{4}{|c|}{ Adopted in FY 2003} \\
\hline & $\begin{array}{c}\text { Life } \\
\text { sciences }\end{array}$ & $\begin{array}{l}\text { Information } \\
\text { sciences }\end{array}$ & $\begin{array}{c}\text { Che mistry, material } \\
\text { sciences }\end{array}$ & Humanities & $\begin{array}{c}\text { Social } \\
\text { sciences }\end{array}$ & $\begin{array}{l}\text { Medical } \\
\text { sciences }\end{array}$ & $\begin{array}{l}\text { Mechanical } \\
\text { engineering }\end{array}$ & $\begin{array}{c}\text { Mathe matics and } \\
\text { physics }\end{array}$ \\
\hline Before the COE & 28.56 & 5.89 & 13.75 & 0.79 & 0.70 & 25.22 & 3.63 & 9.20 \\
\hline After the COE & 37.39 & 8.12 & 16.19 & 0.96 & 0.99 & 31.17 & 5.43 & 10.59 \\
\hline Natural increases & 4.15 & 0.74 & 2.32 & 0.00 & 0.17 & 2.51 & 1.38 & 3.85 \\
\hline The COE effects & $\begin{array}{r}4.674 * * * \\
(1.456)\end{array}$ & $\begin{array}{r}1.488 * * \\
(0.716)\end{array}$ & $\begin{array}{r}0.118 \\
(0.888)\end{array}$ & $\begin{array}{r}0.169 \\
(0.193)\end{array}$ & $\begin{array}{r}0.117 \\
(0.201)\end{array}$ & $\begin{array}{r}3.435 * * \\
(1.368)\end{array}$ & $\begin{array}{r}0.419 \\
(0.443)\end{array}$ & $\begin{array}{r}-2.457 * * \\
(1.149)\end{array}$ \\
\hline
\end{tabular}

*** $\times 0.01 ; * * p<0.05 ; * p<0.1$

Robust standard errors are shown in parentheses. 
Table 3: The increased effects classified according to the universities and the major in the life sciences

\begin{tabular}{|c|c|c|c|c|c|c|}
\hline & \multicolumn{2}{|c|}{ Classified according to the univ. } & \multicolumn{4}{|c|}{ Classified according to the major } \\
\hline & $\begin{array}{l}\text { National and public } \\
\text { univ. ( } 22 \text { teams) }\end{array}$ & $\begin{array}{l}\text { Private univ. } \\
\text { (6 teams) }\end{array}$ & $\begin{array}{l}\text { Life sciences } \\
(3 \text { teams })\end{array}$ & $\begin{array}{l}\text { Biological sciences } \\
\text { (4 teams) }\end{array}$ & $\begin{array}{l}\text { Biological mechanisms } \\
\text { and functions ( } 5 \text { teams) }\end{array}$ & $\begin{array}{c}\text { Others } \\
\text { (11 teams) }\end{array}$ \\
\hline $\begin{array}{l}\text { The ave rage increased effects } \\
\text { in the number of papers }\end{array}$ & 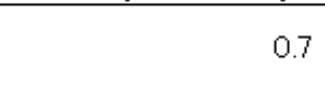 & 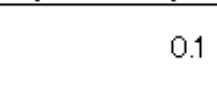 & 0.7 & 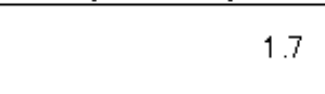 & (2) & 0.4 \\
\hline $\begin{array}{r}\text { The average increased effects } \\
\text { in the citations }\end{array}$ & 6.4 & 1.5 & 8.8 & 0.3 & 8.5 & 7.8 \\
\hline
\end{tabular}


Table 4: The increased effects classified according to the universities and the major in the information sciences

\begin{tabular}{|c|c|c|c|c|c|}
\hline & \multicolumn{2}{|c|}{ Classified according to the univ. } & \multicolumn{3}{|c|}{ Classified according to graduate course } \\
\hline & $\begin{array}{l}\text { National and public } \\
\text { univ. (15 teams) }\end{array}$ & $\begin{array}{l}\text { Private univ. } \\
\text { (5 teams) }\end{array}$ & $\begin{array}{l}\text { School of information } \\
\text { sciences ( } 7 \text { teams) }\end{array}$ & $\begin{array}{c}\text { School of engineering } \\
\text { (6 teams) }\end{array}$ & $\begin{array}{l}\text { School of science and } \\
\text { engineering ( } 6 \text { teams) }\end{array}$ \\
\hline $\begin{array}{l}\text { The ave rage increased effects } \\
\text { in the number of papers }\end{array}$ & 0.1 & 0.0 & (2) & 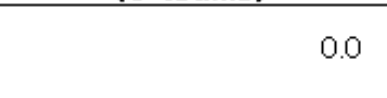 & -0.1 \\
\hline $\begin{array}{l}\text { The average increased effects } \\
\text { in the citations }\end{array}$ & 0.9 & 4.8 & 1.6 & 0.3 & 4.2 \\
\hline
\end{tabular}


Table 5: The increased effects classified according to the universities and the major in the chemistry, material sciences

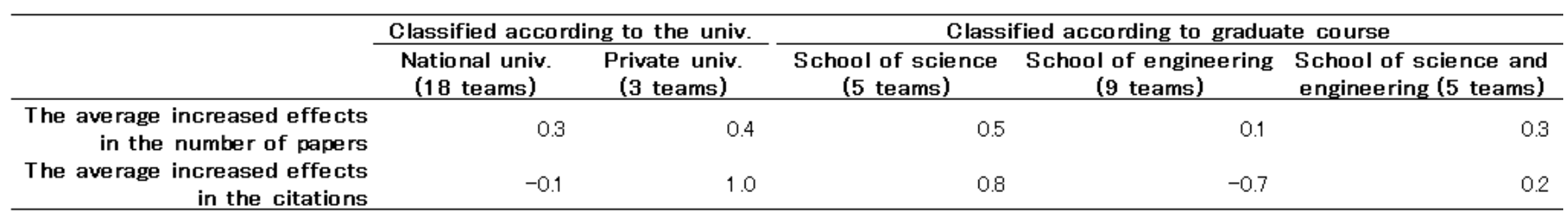


Table 6: The increased effects classified according to the universities and the major in the humanities

\begin{tabular}{|c|c|c|c|c|c|}
\hline & \multicolumn{2}{|c|}{ Classified according to the univ. } & \multicolumn{3}{|c|}{ Classified according to the major } \\
\hline & $\begin{array}{l}\text { National and public } \\
\text { univ. (14 teams) }\end{array}$ & $\begin{array}{l}\text { Private univ. } \\
\text { (6 teams) }\end{array}$ & $\begin{array}{c}\text { Literature and } \\
\text { culture(15 teams) }\end{array}$ & $\begin{array}{l}\text { Education } \\
\text { (2 teams) }\end{array}$ & $\begin{array}{c}\text { Human development, } \\
\text { behavioral studies ( } 3 \text { teams) }\end{array}$ \\
\hline $\begin{array}{l}\text { The average increased effects } \\
\text { in the number of papers }\end{array}$ & 0.1 & 0.0 & 0.0 & 0.0 & 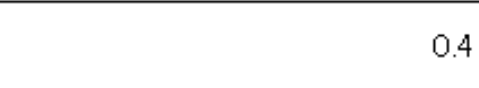 \\
\hline $\begin{array}{r}\text { The average increased effects } \\
\text { in the citations }\end{array}$ & 0.2 & 0.1 & 0.0 & -0.6 & 1.3 \\
\hline
\end{tabular}


Table 7: The increased effects classified according to the universities and the major in the social sciences

\begin{tabular}{|c|c|c|c|c|c|c|c|c|c|}
\hline & \multicolumn{2}{|c|}{ Classified according to the univ. } & \multicolumn{6}{|c|}{ Classified according to the major } & \multirow{3}{*}{$\begin{array}{c}\text { Arts and } \\
\text { letters } \\
\text { (1 team) }\end{array}$} \\
\hline & \multirow{2}{*}{$\begin{array}{l}\text { National and public } \\
\text { univ. (17 teams) }\end{array}$} & \multirow{2}{*}{$\begin{array}{l}\text { Private univ. } \\
\text { (8 teams) }\end{array}$} & \multirow{2}{*}{$\begin{array}{l}\text { Law and } \\
\text { politics } \\
\text { (8 teams) }\end{array}$} & \multirow[t]{2}{*}{ Economics } & \multicolumn{2}{|c|}{ and manage ment (11 teams) } & \multirow{2}{*}{$\begin{array}{l}\text { Policy studies } \\
\text { (5 teams) }\end{array}$} & \multirow{2}{*}{$\begin{array}{l}\text { Sociology } \\
\text { (2 teams) }\end{array}$} & \\
\hline & & & & & $\begin{array}{l}\text { Economics } \\
\text { (8 teams) }\end{array}$ & $\begin{array}{l}\text { Manage ment } \\
\text { (3 teams) }\end{array}$ & & & \\
\hline $\begin{array}{r}\text { The average increased effects } \\
\text { in the citations }\end{array}$ & 0.29 & -0.03 & -0.05 & 0.48 & 0.30 & 0.98 & 0.27 & -0.12 & -0.91 \\
\hline
\end{tabular}


Table 8: The increased effects classified according to the universities and the major in the medical sciences

\begin{tabular}{|c|c|c|c|c|c|c|}
\hline & \multicolumn{2}{|c|}{ Classified according to the univ. } & \multicolumn{4}{|c|}{ Classified according to the major } \\
\hline & $\begin{array}{l}\text { National and public } \\
\text { univ. ( } 26 \text { teams) }\end{array}$ & $\begin{array}{l}\text { Private univ. } \\
\text { (9 teams) }\end{array}$ & $\begin{array}{l}\text { Medical science } \\
\text { (22 teams) }\end{array}$ & $\begin{array}{l}\text { Nursing science } \\
\quad(3 \text { teams })\end{array}$ & $\begin{array}{l}\text { Medical and dental } \\
\text { (2 teams) }\end{array}$ & $\begin{array}{c}\text { Others } \\
\text { (2 teams) }\end{array}$ \\
\hline $\begin{array}{l}\text { The average increased effects } \\
\text { in the number of papers }\end{array}$ & 1.1 & 0.7 & 1.5 & -1.3 & -0.6 & 0.7 \\
\hline $\begin{array}{r}\text { The average increased effects } \\
\text { in the citations }\end{array}$ & 4.1 & 2.6 & 3.7 & -1.6 & 5.4 & -0.5 \\
\hline
\end{tabular}


Table 9: The increased effects classified according to the universities and the major in the mechanical engineering

\begin{tabular}{|c|c|c|c|c|c|}
\hline & \multicolumn{2}{|c|}{ Classified according to the univ. } & \multicolumn{3}{|c|}{ Classified according to the major } \\
\hline & $\begin{array}{l}\text { National and public } \\
\text { univ. (17 teams) }\end{array}$ & $\begin{array}{l}\text { Private univ. } \\
\text { (5 teams) }\end{array}$ & $\begin{array}{c}\text { Environmental } \\
\text { engineering ( } 9 \text { teams) }\end{array}$ & $\begin{array}{c}\text { Mechanical } \\
\text { engineering ( } 8 \text { teams) }\end{array}$ & Others ( 2 teams) \\
\hline $\begin{array}{l}\text { The ave rage increased effects } \\
\text { in the number of papers }\end{array}$ & 0.4 & -0.1 & 0.1 & 0.2 & 0.5 \\
\hline $\begin{array}{r}\text { The average increased effects } \\
\text { in the citations }\end{array}$ & 0.9 & -1.0 & 1.5 & -0.3 & -0.1 \\
\hline
\end{tabular}


Table 10: The increased effects classified according to the universities and the major in the mathematics and physics

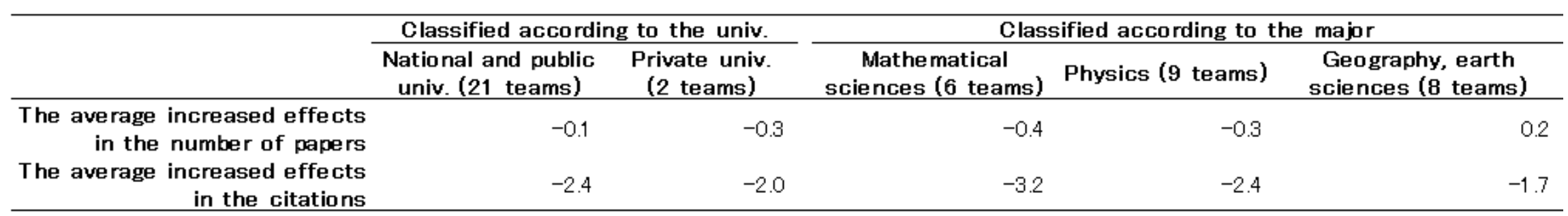

